\title{
A mixed top-down and bottom-up methodology in spatial segregation of emissions based on GIS tools
}

\author{
M. Dios ${ }^{1}$, J. A. Souto ${ }^{1}$, J. J. Casares ${ }^{1}$, N. Gallego ${ }^{2}$, A. Sáez ${ }^{2}$, \\ M. L. Macho ${ }^{2}$, D. Cartelle ${ }^{3}$ \& J. M. Vellón ${ }^{3}$ \\ ${ }^{1}$ University of Santiago de Compostela, Spain \\ ${ }^{2}$ Laboratorio de Medio Ambiente de Galicia, Consellería de Medio \\ Ambiente, Territorio e Infraestructuras, Xunta de Galicia, Spain \\ ${ }^{3}$ Troposfera S.C., Ferrol, Spain
}

\begin{abstract}
Gridded chemical transport models are often used for the assessment of air quality. For European continental scale the EMEP emissions inventory with a low $50 \times 50 \mathrm{~km}^{2}$ resolution is yearly available. However, current air quality models are usually applied with higher spatial resolution, in order to obtain representative results, especially in regional domains; therefore, a simple topdown approach based in the spatial interpolation of EMEP emissions is not appropriate. On the other hand, a bottom-up approach requires a huge amount of data to estimate the emissions source-by-source, which are not always justified for all the sources.

The aim of this work is the development and application of a mixed top-down and bottom-up methodology for high resolution emissions inventories, based on EMEP emission data and other emissions data source (PRTR, UNFCCC and LRTAP). The emissions of the main industrial and road traffic sources $(>50000$ inhabitants cities, motorways) were obtained by a bottom-up approach, with industrial emissions considered from point sources. Other emissions from sparse sources are estimated following a top-down approach, based on the EMEP inventory, following a spatial segregation methodology which considers different geographical parameters, which are dependent on the source type.

Data processing was performed using ArcMap GIS, following the CORINAIR structure [3]. Therefore, results are easily updatable and they can be
\end{abstract}


analysed jointly to the geographical parameters, in order to check the inventory coherence before its application to an air quality model.

Keywords: emissions inventory, EMEP, top-down, bottom-up, GIS.

\section{Introduction}

The degradation of the environment is partly caused by the emissions from the anthropogenic activities, such as energy production, manufacture industry, transport or domestic activities. Air quality analysis and its impacts over human health and ecosystems were traditionally based on experimental measurements from air monitoring stations. However, these measurements are just describing the air quality at specific time and location without identifying clearly any causes of the observed values [4]. The air quality modeling, on the other hand, may set up a deterministic description of the pollution problems, including the analysis of the emission sources, meteorological processes, physical and chemical changes, or even a guide for the implementation of mitigation measures [3].

The compilation of emission information is a critical stage in air quality modeling. Most of the uncertainties and lack of accuracy in the results are assigned to the emissions inventory uncertainty. Because there are not unified criteria for air quality modeling, there are several models in use, different versions, different emissions data, etc. and, consequently, the obtained results can not be compared [5].

Several attempts have been made to characterize and homogenize the emissions inventories and their compilation and calculation procedures. The Convention on Long-range Transboundary Air Pollution CLRTAP in 1979 laid the foundation for the 1984 Co-operative Programme for Monitoring and Evaluation of the Long-Range Transmission of Air Pollutants in Europe, EMEP [7]. Some of the major objectives of EMEP programme are to compile and analyze the emission data and to supply regularly truthful and verified information about emissions to scientific and politic community. These emissions are reported for main pollutants, aerosols, heavy metals and persistent organic pollutants, by sector and geographically referenced over a grid with a spatial resolution of $50 \times 50 \mathrm{~km}^{2}$.

EMEP is based on a top-down approach: the emissions are calculated for a total area and then distributed attending to different down-scaling or allocation patterns related to the emission source. This approach has an acceptable accuracy for global purposes, if the suitable activity parameters are used. But for regional purposes this is maybe inaccurate. The characterization of the emissions from one country or a part of it requires the compilation of specific information of the country: energy profiles, vehicle fleet, population density, land use, and so on. EMEP emissions inventory is not able to represent the inner variability within each EMEP cell, especially for those areas where there are strong spatial gradients in emissions, such as cities or industrial areas. These differences may be more than order of magnitude and the problem is not only the resolution of the emission calculation, but the spatial distribution [7]. 
A bottom-up approach for emissions inventories improves the accuracy of the emissions calculated. It is based on the detailed calculation of the emissions from all the individual sources of an area, which are subsequently aggregated to obtain the emissions from the total area. The characterization of each one of the activities involves the management of large amount of information, which will not always be available, and a great deal of effort for calculation.

Because bottom-up approach is a very time-consuming task and the accuracy of the calculation and distribution of emissions using a top-down approach is not enough, a combined top-down and bottom-up methodology is purposed [7].

The aim of this work is to describe a methodology derived from the combination of bottom-up and top-down approaches and based on EMEP data and other publicly available information sources. This methodology combines reported emissions from the regulations of point industrial processes such as PRTR, Pollutant Release and Transfer Register or UNFCCC United Nations Framework Convention on Climate Change with estimated emissions, calculated by applying internationally recognized emission factors to the appropriate activities statistics; and, in addition, different top-down disaggregation criteria of EMEP inventory. The purposed mixed methodology was applied over the region of Galicia (NW of Spain) and performed by a Geographical Information System (Arcmap GIS). This application enables optimal processing and presentation of emission data and their later application to air quality modeling [8].

\section{Methodology and scope}

\subsection{Description of methodology}

The mixed top-down and bottom-up methodology for spatial segregation of the emissions has to be explained section by section according to the emission source type. The analysis of segregation of emissions for modelling purposes has been studied from different points of view, although it is considered to be a state-of-the-art procedure to be carried out in three steps [9, 10]. First the emissions for all relevant activities are calculated and/or compiled. Then, for all these emission values, different segregation parameters must be assigned to each geographic unit. These key parameters were chosen and assumed to vary with emission source's actual activity levels [11]. In the last step, these already segregated emissions may be uniformly distributed over a regular grid.

The segregation procedure is directly dependant on the spatial characteristics of the emission source. Point sources can be located geographically and therefore, no distribution methodology is required. The emission will be placed where is generated. For line and area sources the segregation is carried out following the three steps procedure stated above, using geographic and statistic information [12]. The methodology and data compiled for the calculation and segregation of the activities are presented in Table 1. 
Table 1: Summary of the approaches and data applied on the different activities.

\begin{tabular}{|c|c|c|}
\hline Activity - SNAP & Emissions & Approach and data collection \\
\hline $\begin{array}{l}\text { Industrial } \\
\mathrm{S} 1, \mathrm{~S} 3, \mathrm{~S} 4\end{array}$ & $\begin{array}{l}\text { Calculated } \\
+ \text { EMEP }\end{array}$ & $\begin{array}{l}\text { Bottom-up for main industrial units. Top- } \\
\text { down for the remainder } \\
\text { - Measured emissions (when available) } \\
\text { - Production level and energy consumption } \\
\text { - Technologies and emission control systems } \\
\text { - Emission factors }\end{array}$ \\
\hline $\begin{array}{c}\text { Domestic and } \\
\text { commercial } \\
\text { S2, S6 }\end{array}$ & EMEP & $\begin{array}{l}\text { Top-down } \\
\text { - Population density by council }\end{array}$ \\
\hline $\begin{array}{l}\text { Road transport } \\
\text { S7 }\end{array}$ & Calculated & $\begin{array}{l}\text { Bottom-up for main cities ( }>50000 \text { inhab.) } \\
\text { and highways. Top-down for the remainder } \\
\text { councils } \\
\text { - Total annual fuel consumption } \\
\text { - Traffic patterns and fleet composition } \\
\text { - Official fleet of vehicles per council } \\
\text { - Floating traffic information for cities } \\
\text { - Information of traffic counters in highways }\end{array}$ \\
\hline $\begin{array}{l}\text { Agriculture } \\
\text { S10 }\end{array}$ & $\begin{array}{l}\text { Calculated } \\
+ \text { EMEP }\end{array}$ & $\begin{array}{l}\text { Bottom-up for registered farms and top- } \\
\text { down for the remainder EMEP emissions } \\
\text { - Farms production and waste management } \\
\text { systems } \\
\text { - Land use patterns: CORINE Land Cover }\end{array}$ \\
\hline $\begin{array}{c}\text { Other } \\
\text { S5, S8, S9 }\end{array}$ & EMEP & $\begin{array}{l}\text { Top-down } \\
\text { - Uniform distribution }\end{array}$ \\
\hline
\end{tabular}

S1: Combustion in energy and transformation industries; S2: Non-industrial combustion;

S3: Combustion in manufacturing industry; S4: Production processes; S5: Extraction and distribution of fossil fuels; S6: Solvent and other product use, S7: Road transport; S8: Other mobile sources and machinery; S9: Waste treatment and disposal; S10: Agriculture.

\subsection{Bottom-up approach}

\subsubsection{Industrial sectors (I)}

The emissions from the industrial enterprises, considered as point sources, were compiled and all available data that were applied: IPPC, PRTR, etc. Data from experimental measurements were considered as a priority; although a detailed revision and validation procedures was taken. These measured values were compared with the emissions obtained with internationally recognized emission factors. In case of inconsistency, theoretical values were used.

\subsubsection{Agriculture (I)}

The livestock farming industry can also be considered as an industrial sector. Those farms which were registered can be dealt with in the same way as the other industrial facilities. 


\subsubsection{Road transport}

The emissions from road transport in major cities and highways were obtained following bottom-up approach. For the calculation of the emissions from traffic in main cities, specific traffic studies were compiled and both internal and floating traffic were taken into account. In case of major highways, information related to the traffic counters needed to be compiled: both the number of driving vehicles on each road and the percentage of heavy traffic.

For coherency reasons, the emission factors were obtained from COPERT 4 software [13]. This is a software tool used world-wide to calculate air pollutant from road transport, developed by the European Environment Agency (EEA). Some simplifications in vehicle fleet distribution were performed; only two distributions of the vehicle fleet where considered: one regional distribution for the traffic in the cities and, for major highways, a variation of this regional distribution was applied, considering the percentage of each type of vehicle: passenger cars, duty vehicles and motorcycles. Emissions were allocated to every municipality and road according to calculations results in each category.

\subsection{Top-down approach}

\subsubsection{Industrial sectors (II)}

Point source data are not available for all processes. Sources may not need to report emissions if these are below a specified reporting threshold, so, not all the industrial emissions were being considered. The contribution of these sources is typically $10 \%$, but for some pollutants this percentage may suppose even a $30-50 \%(9)$. The remainder EMEP emission is suggested to be used; taking away all the industrial emissions for each EMEP cell from the correspondent EMEP emission. These emissions were then uniformly distributed.

\subsubsection{Agriculture (II)}

Livestock farming industry represent just a part of the total emissions from agriculture. Following the reasoning stated above, the remainder EMEP emission for agricultural sector will be uniformly distributed to the areas where the specific activities are assumed to take place. The distribution by land use was using Corine Land Cover patterns [14].

\subsubsection{Residential sectors}

Emissions from space heating and domestic use of solvents are very hard to obtain because of the amount of information that it is necessary to handle. This is why the use of EMEP emission is proposed. The emissions from residential sectors will be distributed to the built-up areas according to population density.

\subsubsection{Other}

In this section S5 (Extraction and distribution of fossil fuels and geothermal energy), S8 (Other mobile sources and machinery) and S9 (Waste treatment and disposal) sectors are included. The contribution of these sectors to the total emissions is not as relevant as the previous sectors; therefore, uniformly 
distributed EMEP emissions were used. For S8 sector, differences between terrestrial and boats emissions were considered.

\subsection{GIS use}

The spatial segregation of emissions applies a mathematical procedure to distribute them over a specific area. The amount and complexity of the information handled makes the use of a Geographical Information System (GIS) software essential for the combination of emissions and geographic information. Capacity of GIS as a support for spatial distribution, parameters allocation, establishment of grids, etc, is especially in favour of environmental procedures. GIS procedures are suitable for both bottom-up and top-down approaches; through the storage and association between the emissions and layers, polygons and/or point models [15].

\subsection{Scope}

The procedure stated below was applied to Galicia, a region in the Northwest corner of the Iberian Peninsula (Figure 1). All the activities and pollutants considered by EMEP were taken into account. The base year for this study was 2008, which was the reference year for the gathered EMEP data. A regular grid of $3 \times 3 \mathrm{~km}^{2}$ of resolution was considered.

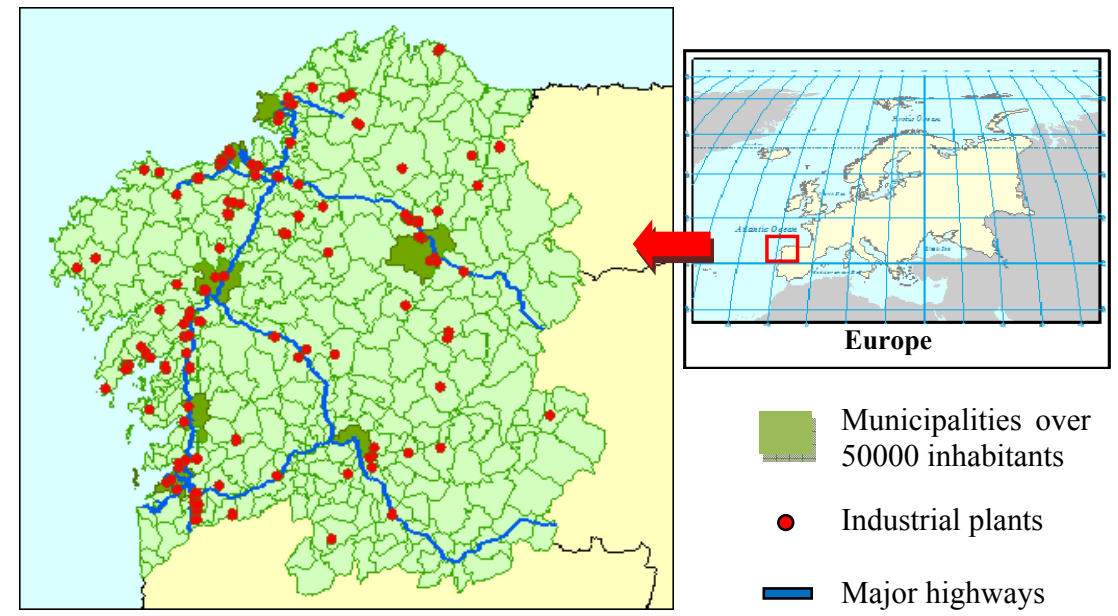

Gallcla (NW of Spaln)

Figure 1: EMEP grid over Galicia - NW of the Iberian Peninsula. Highlighted major cities (over 50,000 inhabitants), highways and main industrial plants. 


\section{Results and discussion}

The results were obtained on a $3 \times 3 \mathrm{~km}^{2}$ regular grid, covering a domain from $10.0^{\circ} \mathrm{W}$ to $6.0^{\circ} \mathrm{W}$, and from $41.0^{\circ} \mathrm{N}$ to $44.8^{\circ} \mathrm{N}$ ( NW of the Iberian Peninsula). This regular grid can be directly applied to air quality modeling purposes.

\subsection{Industrial sectors and agriculture}

The compilation of information from all the public sources available, both emissions directly, production/raw materials consumption, and internationally recognized emission factors, leads to the results summarized in Table 2.

Table 2: Industrial point sources emissions (t) for the main pollutants considered by EMEP distributed by sector and contribution of the emissions (\%) directly obtained from public information sources.

\begin{tabular}{|c|c|c|c|c|c|c|c|}
\hline \multirow{2}{*}{$\begin{array}{c}\text { SNAP } \\
\text { Sector }\end{array}$} & \multicolumn{7}{|c|}{ Emissions (t) } \\
\cline { 2 - 8 } & $\mathrm{CO}$ & $\mathrm{NH}_{3}$ & $\mathrm{NMVOC}$ & $\mathrm{NO}_{\mathrm{x}}$ & $\mathrm{PM}_{\text {coarse }}$ & $\mathrm{PM}_{2.5}$ & $\mathrm{SO}_{\mathrm{x}}$ \\
\hline $\mathrm{S} 1$ & 3455.8 & 51.5 & 156.3 & 18381.2 & 405.2 & 318.0 & 18240.6 \\
\hline $\mathrm{S} 3$ & 21681.7 & 146.9 & 781.2 & 5869.8 & 115.9 & 501.7 & 11182.4 \\
\hline $\mathrm{S} 4$ & 4028.6 & 3586.7 & 10478.8 & 3227.3 & 356.9 & 1596.6 & 7550.2 \\
\hline $\mathrm{S} 10$ & - & 1690.9 & - & - & - & - & - \\
\hline TOTAL & 29166.1 & 5476.0 & 11416.4 & 27478.2 & 878.0 & 2416.3 & 36973.1 \\
\hline $\begin{array}{c}\text { Direct public } \\
\text { information }\end{array}$ & $98.7 \%$ & $38.3 \%$ & $63.3 \%$ & $98.0 \%$ & $52.5 \%$ & $0.0 \%$ & $99.0 \%$ \\
\hline
\end{tabular}

In this table, the percentage of the emissions obtained directly from public sources is also presented. A variable contribution from public information between pollutants can be observed. This becomes even more significant when considering pollutants such as PM2.5 (particles less than 2.5 micrometers in diameter) or heavy metals, for which very limited data are available.

These emission values were geographically located over the regular grid and, also over the EMEP grid, in order to be simultaneously processed within the EMEP emissions. For each EMEP cell, a remainder of every EMEP emission was calculated and uniformly distributed over the regular grid, for S1, S3 and S4 SNAPs. Finally, S10 SNAP emissions were allocated as a function of land use.

An example of this procedure is shown in Figure 2 for SOx and S3 SNAP sector. Due to the need to redistribute the remainder of EMEP emissions, the comparison with EMEP inventory for industrial sectors shows significant differences not only on spatial distribution, but also in the magnitude of the total emissions over each cell. 


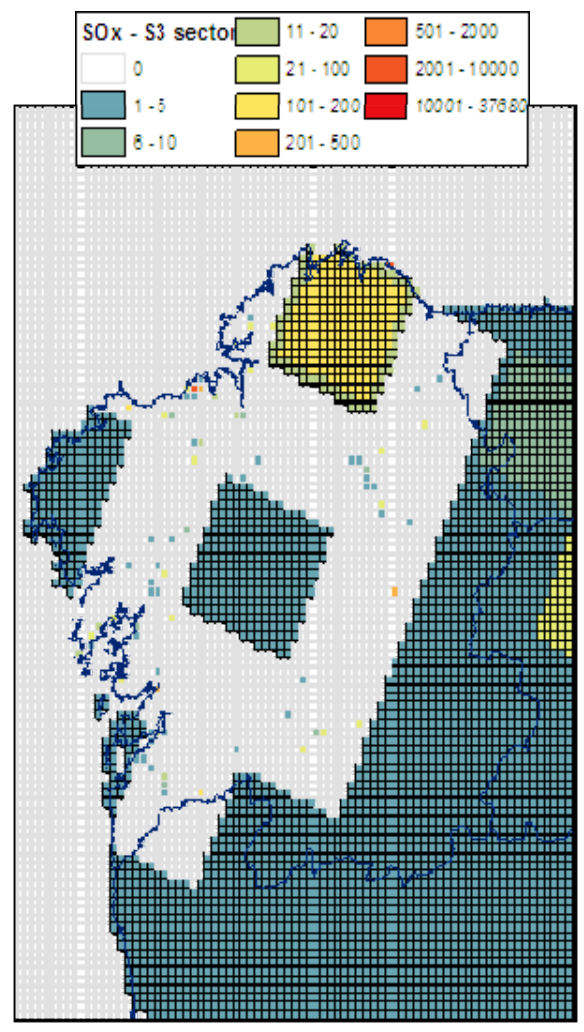

a) Mixed bottom-up and top-down inventory

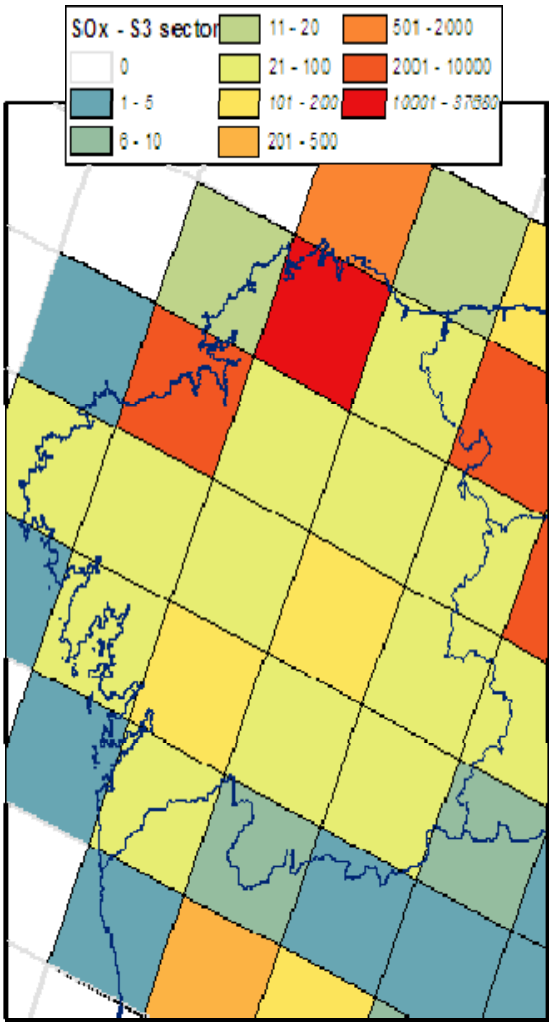

b) EMEP inventory

Figure 2: Comparison between 2008 mixed bottom-up and top-down and EMEP inventories (t). Pollutant: $\mathrm{SO}_{\mathrm{x}}$. SNAP: S3 (Industrial combustion).

\subsection{Road transport}

The calculated emissions from road transport with COPERT 4 are significantly higher than those proposed by EMEP. An example of the emissions from this sector is presented in Figure 3, where $\mathrm{NO}_{\mathrm{x}}$ pollutant was selected, because it is typically associated with traffic pollution. 

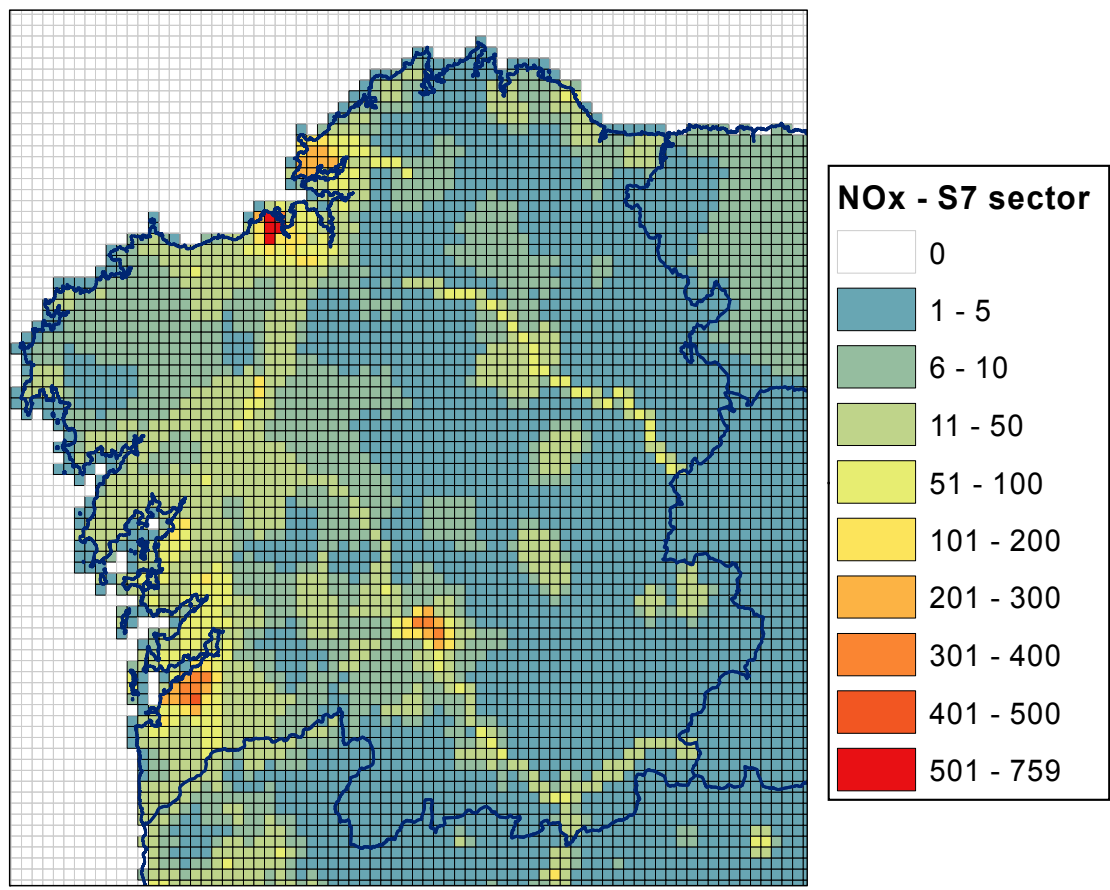

Figure 3: 2008 mixed bottom-up and top-down inventory $(\mathrm{t})$. Pollutant: $\mathrm{NO}_{\mathrm{x}}$ (t) SNAP: S7 (Road transport).

Seven cities over 50,000 inhabitants were identified. First, the emissions from these cities were calculated, taking into account both internal and floating traffic. Second, $795 \mathrm{~km}$ belonging to 9 highways that serve up to 694,000 vehicles per day were also considered; the percentage of heavy vehicles reaches $27.6 \%$ in some stretches of these highways [16].

\subsection{Residential sector}

It can be observed that the distribution of EMEP emissions for residential sector is independent of the population or build-up patterns. The most populated areas, and consequently, the most developed, are not assigned the higher emissions in EMEP. This fact is shown in Figure 4, where the population density is presented for the emissions of $\mathrm{CO}$ and NMVOC for S2 (Non industrial combustion) and S6 (Solvent and other product use) SNAPs sectors, respectively.

The improvement proposed for this sector is a distribution of EMEP emissions attending to population statistical data [16]. The data were disaggregated to municipal level, and then redistributed over the regular grid. An example of the distribution of emissions for residential sectors is presented in Figure 5, where the emissions of CO for SNAP S2 are shown. 


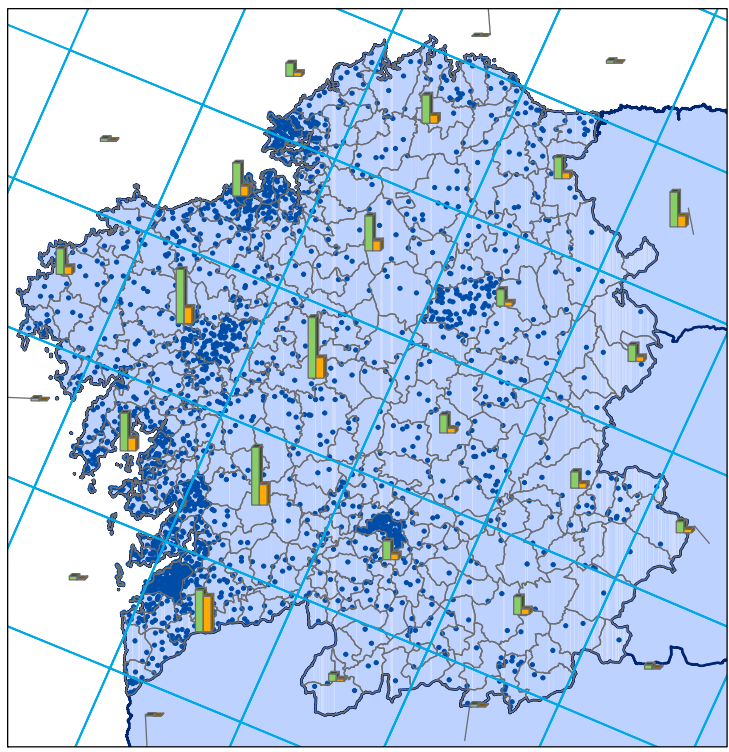

\section{EMEP inventory}

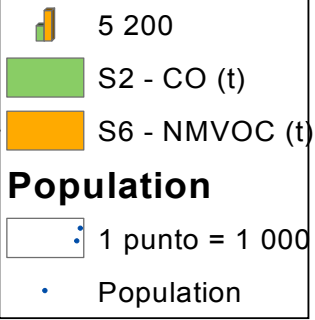

Figure 4: Comparison of EMEP distribution for emissions from residential sectors and population density disaggregated to municipal level. Pollutant: CO (t) SNAPs: S2 (Non industrial combustion) Pollutant: NMVOC (t) SNAP: S6 (Solvent and other product use).
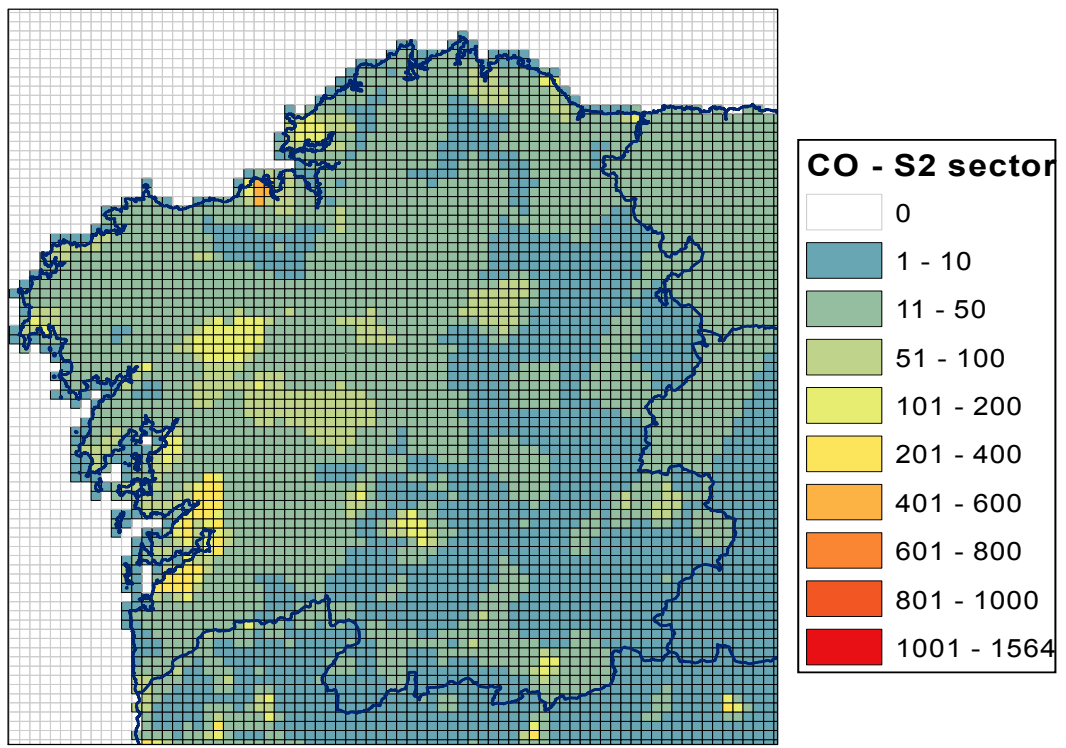

Figure 5: 2008 mixed bottom-up and top-down inventory (t). Pollutant: CO (t) SNAP: S2 (Non industrial combustion). 


\section{Concluding remarks}

The combination of top-down based on EMEP data and bottom-up approaches for emissions inventories improves the accuracy of the emissions calculation. The bottom-up approach applied to industrial and transport sources, makes feasible the inclusion of specific information data by area.

When comparing the new inventory to EMEP inventory (disaggregated uniformly), significant differences in the spatial distribution of both point and area sources (usually, more concentrated in specific areas with the improved inventory) are observed.

As this methodology is based in both PRTR and EMEP data and other public information, consequently, it is possible to improve and update periodically the emissions inventories, which could be directly used in air quality models.

\section{Acknowledgements}

The Galician regional 'Consellería de Innovación e Industria' is acknowledged for the PhD grant of M. Dios ("María Barbeito" Programme, Xunta de Galicia). This work was developed with the financial support of Laboratorio de Medio Ambiente de Galicia (Xunta de Galicia), Troposfera S.C. and the project “XIMERE/FUXIMERE” (10MDS009E) (PGIDT, Xunta de Galicia).

\section{References}

[1] CEIP EMEP. Centre on Emission Inventories and Projections. Officially reported emission data. . http://www.ceip.at/.[Online].

[2] Pulles T., Heslinga D. The Art of Emission Inventorying TNO. Utrecht. TNO, 2010.

[3] EEA European Environment Agency. EMEP/EEA Air Pollutant Emission Inventory Guidebook 2009. Technical Report No 6/2009. Copenhagen: European Environment Agency, 2009.

[4] EEA European Environment Agency. The application of models under the European Union's Air Quality Directive: A technical reference guide. Technical report No 10/2011. Copenhagen, 2011.

[5] Monteiro, A., et al. Using Air Quality Modelling to Improve Air Emission Inventories. Proceedings of 17th Annual International Emission Inventory Conference "Inventory Evolution - Portal to Improved Air Quality" Portland, Oregon, 2008.

[6] UNECE United Nations Economic Commission for Europe. Protocol to the Convention on Long-Range Transboundary Air Pollution on Long-term Financing of the Co-operative Programme for Monitoring and Evaluation of the Long-Range Transmission of Air Pollutants in Europe (EMEP). Geneva, Switzerland, 1984.

[7] Butler, T.M., et al. The representation of emissions from megacities in global emission inventories. Atmospheric Environment, Volume 42, Issue 4, pp. 703-719, 2008. 
[8] Karvosenoja, N. Emission scenario model for regional air pollution. Monographs of the Boreal Environment Research. Monograph No. 32. Finnish Environment Institut, Helsinki, Finland, 2008.

[9] Bush, T. et al. NAEI UK Emission Mapping Methodology 2005. AEAT/ENV/R/2511 - Issue 1. National Atmospheric Emissions Inventory. s.1., United Kingdom: AEA Energy \& Environment, 2008.

[10] Maes, J. et al. Spatial surrogates for the disaggregation of CORINAIR emission inventories. Atmospheric Environment. Volume 43, Issue 6, pp. 1246-1254, 2008.

[11] Hamal, Kh.V. Carbon Dioxide Emissions Inventory with GIS. Artificial Intelligence journal, pp. 55-62, 2008.

[12] Wilson, S.J., et al. Mapping the spatial distribution of global anthropogenic mercury atmospheric emission inventories. Atmospheric Environment Volume 40, Issue 24, pp. 4621-4632, 2007.

[13] Aristotle University Thessaloniki. Greece. http://lat.eng.auth.gr/copert/. COPERT 4 (version 8.0) Computer Programme to Calculate Emissions from Road Traffic. http://lat.eng.auth.gr/copert/ [Online], 2009.

[14] EIONET European Topic Centre on Spatial Information and Analysis. Corine Land Cover 2006. http://sia.eionet.europa.eu/CLC2006. [Online].

[15] Goodchild, M. F. et al. Environmental modeling with GIS. Oxford University Press, 1993.

[16] IGE (Galician Statistical Institute) http://www.ige.eu. [Online]. 